\title{
MOLECULAR ANALYSIS OF THE GENETIC DIVERSITY OF POPULATIONS OF SWEET CLOVER (Melilotus dentatus Pers.)
}

A.N. Muntyan, V.S. Belova, E.P. Chizhevskaya, M.L. Rumyantseva, B. V. Simarov, E.E. Andronov

All-Russia Research and Development Institute for Agricultural Microbiology, RAAS, St. Petersburg-Pushkin 196608, Russia

e-mail: eeandr@gmail.com

Received May 25, 2012

S u m m a r y

In the studies of Melilotus dentatus Pers. populations from different geographically remote areas (North Caucasus and Kazakhstan), a compex approach of intra- and inter-population analysis of taxonomically important molecular markers (ITS) was used. The analysis of receptor gene $\mathrm{nfr} 5$ was also made. It is shown that the Melilotus dentatus Pers. plants differ at both intra- and inter-population levels. A consolidation of sweet clover's populations to clusters is observed according to their geographic location. An independent distribution of populations on receptor part of $\mathrm{nfr} 5$ gene concerning cluster structure of ITS region is determined.

Keywords: Melilotus dentatus Pers., genetic diversity, nfr5 gene.

In global agriculture, sweet clover is a fodder plant less important than other leguminous forage grasses. At the same time, detailed recent studies show a number of valuable economical properties of Melilotus dentatus Pers.: high drought resistance, winter hardiness, along with better immunity against pests and diseases compared with other legumes (1), and better consumption by animals due to lower content of coumarin (2). Its ability to grow on saline lands allows using sweet clover in soil recultivation through the creation of saline-resistant legume-rhizobial complex. Such programs require the plants with improved symbiotic efficiency, which is largely determined by the genotype.

The peculiarity of legume-rhizobium symbiosis is a signal exchange between both partners whose signaling molecules trigger the mechanism of formation of a specialized new organ - nodule. In response to the specific inducers - flavonoids released in soil by a host plant, nitrogen-fixing bacteria start the production of signaling molecules (Nod-factors) that initiate the formation of root nodules in leguminous plants (3). All Nod-factors are lypochytho-oligosaccharides. Legume plants have seven genes presumably involved in signaling recognition and interaction with symbiotic rhizobia (4). The family of $L Y K$ genes is of particular interest, which include $n f r 1$ and $n f r 5$ first identified in Lotus japonicus $(3,5)$, Sym10 and Sym2 in Pisum sativum (3), as well as NFP gene in diploid alfalfa $(6,7)$. These genes encode LysM-containing receptor kinase, and they have domain structure typical for plants: extracellular LysM-domains - probable participants in the reception of Nod-factor, a transmembrane domain, and an intracellular domain of serine / threonine kinase.

The genes containing LysM-encoding regions (LysM-motifs) belong to an ancient and quite diverse group widespread in all kingdoms except Archaea (7). Phylogenetic analysis has shown that some sequences of bacterial LysM-motifs have common roots with nucleotide sequences of fungi, plants, insects and animals. This allowed suggesting that one group of these genes had been formed before the divergence of plants and animals, while the other group is the result of convergent evolution. A structural resemblance of LysM-containing protein kinase and the peptidogycan component of bacterial cell wall confirms the involvement of receptor proteins NFR1 and NFR5 in the recognition of Nod-factor and its transfer to following links of a signaling cascade leading to nodulation (7). However, a current knowledge of origins and functioning of these receptor genes is still incomplete.

Today, many molecular genetic techniques allow investigating the genetic diversity and population changes of crops (8). The purpose of this research was molecular analysis of genetic variation in sweet clover (Melilotus dentatus Pers.) samples collected in different geographically remote areas (Sub-Aral region and the Northern Caucasus).

Technique. Seeds of sweet clover were harvested during ripening (October, 2000) in the territory of Kazakhstan — sites № $31\left(49^{\circ} 56^{\prime} \mathrm{N}, 58^{\circ} 92^{\prime} \mathrm{W}\right)$ and № 57 (49 $\left.59^{\prime} \mathrm{N}, 57^{\circ} 71^{\prime} \mathrm{W}\right)$, and in Krasnodarsky Krai of Russia (Northern Caucasus) — site № 51 $\left(43^{\circ} 52^{\prime} \mathrm{N}, 39^{\circ} 22^{\prime} \mathrm{W}\right)$. The seeds were sterilized with concentrated sulfuric acid for $10 \mathrm{~min}$, washed thoroughly with sterile water and germinated in Petri dishes for 2 days at $4{ }^{\circ} \mathrm{C}$. Further studies were performed on 20 seedlings selected from each population.

Genomic DNA was isolated from 2-day-old seedlings by chloroform extraction with CTAB-buffer (9). The plant material was thoroughly homogenized, then suspended in $\mathrm{CTAB}$ and incubated at $65{ }^{\circ} \mathrm{C}$ for 60 min. After the chloroform extraction, a supernatant containing DNA was precipitated with an equal volume of isopropanol and then washed with $70 \%$ ethanol. The DNA sample was resuspended in $50 \mathrm{ul}$ of deionized water.

RAPD-fingerprinting was performed using a decamer primer FS-27 (5'-AGCCGGCCTT-3') (10). Amplification was conducted in a thermocycler My Cycler ("Bio Rad", USA) under the following regime: denaturation 3 min at $95{ }^{\circ} \mathrm{C}$; 40 cycles: denaturation $-30 \mathrm{~s}$ at $94{ }^{\circ} \mathrm{C}$, annealing of primers $-30 \mathrm{~s}$ at $37{ }^{\circ} \mathrm{C}$, elongation $-3 \mathrm{~min}$ at $68{ }^{\circ} \mathrm{C}$; final synthesis $-3 \mathrm{~min}$ at $72{ }^{\circ} \mathrm{C}$. RAPD was carried out in a reaction mixture of 201 containing $101 / 2$ buffer $(670 \mathrm{mM}$ Tris- $\mathrm{HCl}, \mathrm{pH} 9,1 ; 166 \mathrm{mM}$ ammonium sulfate, $20 \mathrm{mM}$ magnesium chloride, 0,1\% Tween 20), dNTP (concentration of each 0,15 mmol), primer (15 pM), 1,5 units of Taqpolymerase ("Fermentas", Lithuania) and 1 ul of genomic DNA (10-12 ng). The products of amplification were separated in $2 \%$ agarose gel containing ethidium bromide with $0,5 \frac{1}{2}$ TAE buffer.

Amplification of ITS spacer of plant DNA was conducted using primers ITS4 (5'-TCCTCCGCTTATTGATATGC-3 ') and ITS5 (5'-GGAA-GTAAAAGTCGTAACAAGG-3') (11) in a thermocycler My Cycler ("Bio Rad", USA). The reaction mixture of 20 ul contained $10 \times$ buffer, dNTP (concentration of each $0,15 \mathrm{mM}$ ), the mix of primers ITS4 and ITS5 (15 pM), 1,5 units of Taqpolymerase (5 units/ul), and $1 \mathrm{ul}$ of genomic DNA (10-12 ng). PCR protocol: denaturation $3 \mathrm{~min}$ at $95{ }^{\circ} \mathrm{C} ; 30 \mathrm{cycles}-30 \mathrm{~s}$ at $95{ }^{\circ} \mathrm{C}$, $30 \mathrm{~s}$ at $55{ }^{\circ} \mathrm{C}, 1 \mathrm{~min}$ at $72{ }^{\circ} \mathrm{C}$; final elongation $4 \mathrm{~min}$ at $72{ }^{\circ} \mathrm{C}$. PCR for a fragment of $n f r 5$ gene was performed using a pair of degenerate primers - nfr5-for3 (5'-AAGTCT-TGGTTGTTAYTTGCCA-3 ') and nfr5-Grev3 (5'-TGCAGTCTCAGCTAATGAAGTAC-3'). PCR protocol: $3 \mathrm{~min}$ at $95{ }^{\circ} \mathrm{C} ; 30$ cycles $-30 \mathrm{~s}$ at $94{ }^{\circ} \mathrm{C}, 30 \mathrm{~s}$ at $42{ }^{\circ} \mathrm{C}, 1 \mathrm{~min}$ at $72{ }^{\circ} \mathrm{C} ; 4 \mathrm{~min}$ at $72{ }^{\circ} \mathrm{C}$.

To determine the nucleotide sequence of DNA, the amplification products were cloned with pTZ57R/T vector ("Fermentas", Lithuania). Sequencing was performed with standard M13 primers on an automatic device CEQ ${ }^{\mathrm{TM}} 8000$ Genetic Analysis System 
("Beckman Coulter, Inc.", USA). Each sequence was analyzed in two directions. The data on nucleotide sequences of ITS spacer and $n f r 5$ gene were statistically processed by software of the sequencer CEQ ${ }^{\text {TM }} 8000$ Genetic Analysis System. Alignment and assembly of nucleotide and protein sequences was carried out in the program Vector NTI Suit 8 (www.invitrogen.com). Phylogenetic trees were constructed using the programs ClustalX (www.clustal.org) and FPQuest ("Bio Rad", USA).

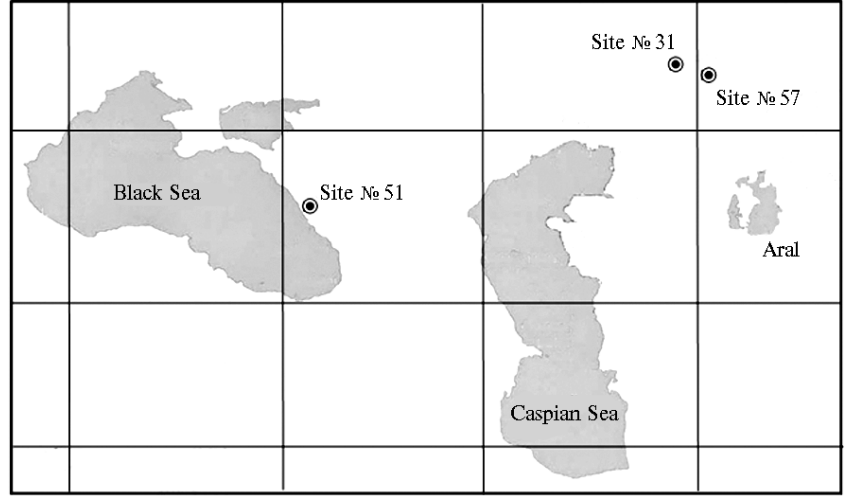

Fig. 1. Geographical location of Melilotus dentatus Pers. populations - sources of studied seeds.

variation in minor fragments) and their profiles were clearly differen from the population of Northern Caucasus (although several samples had identical RAPD-profiles). Further analysis of ITS spacer and the receptor fragment of $n f r 5$ gene was performed using three samples of Melilotus dentatus Pers. having the most polymorphic RAPD-profiles selected from each population (Fig. 2).

A

$\mathrm{B}$

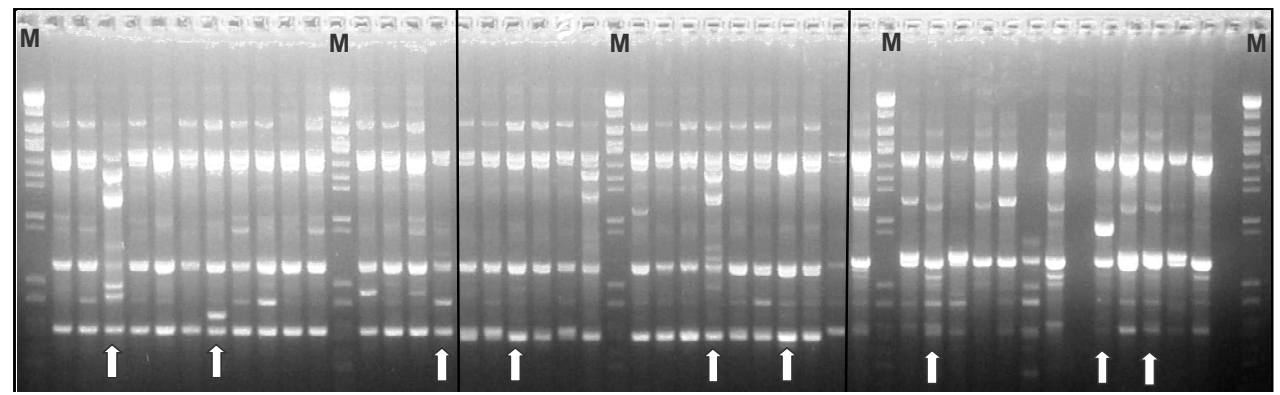

Fig. 2. RAPD-fingerprinting of Melilotus dentatus Pers. samples collected in Sub-Aral region (A and B, resp., sites № 31 and № 57) and in the Northern Caucasus (C, site № 51). M - molecular weight marker $\lambda /$ BstEII. Arrows point on RAPD-profiles used in analysis of ITS spacer and the receptor fragment of $n f r 5$ gene.

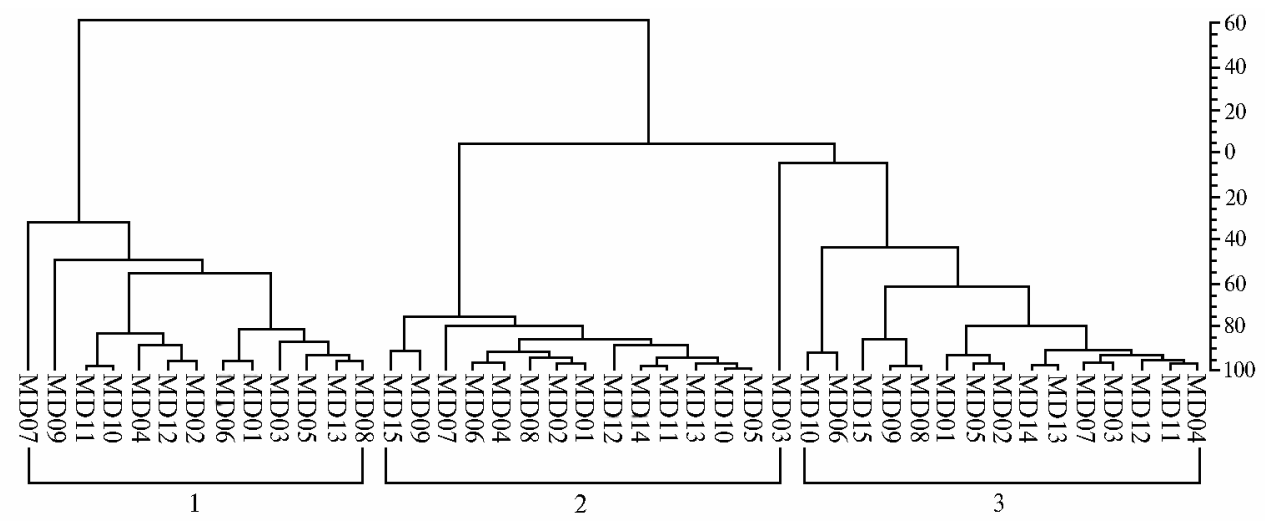

Fig. 3. Dendrogram of phylogenetic relations of the studied populations of Melilotus dentatus Pers. (MD) from the Northern Caucasus (1, site № 51) and Sub-Aral region (1 and 2, resp., sites № 31 and № 57) constructed upon the results of RAPD-fingerprinting.

The sequenced ITS of rDNA included a high-conservative sequence of 5,8S-subunit of RNA and two transcribed spacers ITS1 and ITS2. Specific properties of these spacers are multi-copy occurrence, small size (600-700 bp), and coordinated evolution (11), which makes them taxonomically significant molecular markers in phylogenetic studies of higher plants (12) .

The examined nucleotide sequences of ITS spacer had a size of $687 \mathrm{bp}$; these findings were used to construct the dendrogram showing phylogenetic relations of the studied populations (Fig. 4). The obtained data were fully consistent with the results of RAPDfingerprinting. In both cases, the populations of sweet clover from Sub-Aral region and the Northern Caucasus were found to belong to separate clusters whose degree of difference corresponded to isolated populations.

Detailed analysis of nucleotide sequences of ITS spacer revealed point substitutions in ITS1, 5,8S and ITS2 (Fig. 5). In ITS2, it was identified three variable sites with nucleotide substitutions (positions 494, 611 and 648) uniquely indicating the differences between the studied populations from Sub-Aral and the Northern Caucasus. Knowing from the literature that ITS1 and ITS2 are considered as evolutionary conjugate spacers, it can be assumed that genetic changes might affect them both. However, in the studied samples of sweet clover, the maximum of polymorphic sites was observed in ITS2 (Fig. 5). 


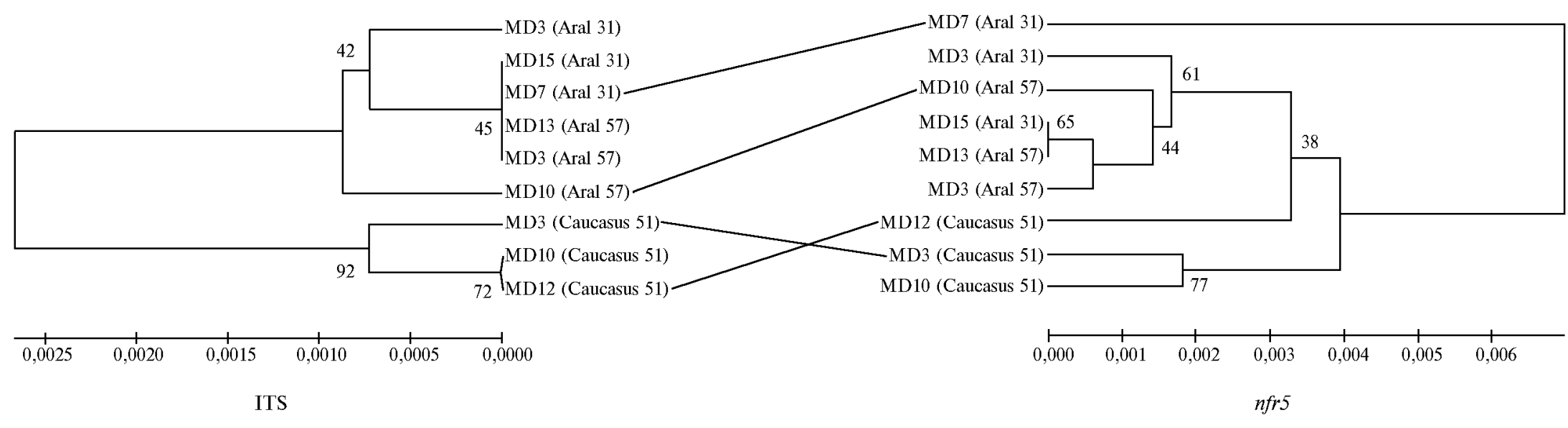

Fig. 4. Dendrograms of phylogenetic relations for ITS spacer (internal transcribed spacer of rDNA) and the receptor fragment of $\boldsymbol{n f r} 5$ gene (receptor protein NFR5) in studied samples of Melilotus dentatus Pers. (MD) from the Northern Caucasus (site № 51 — Caucasus 51) and Sub-Aral region (sites № 31 and № 57 — resp., Aral 31 and Aral 57 ). 


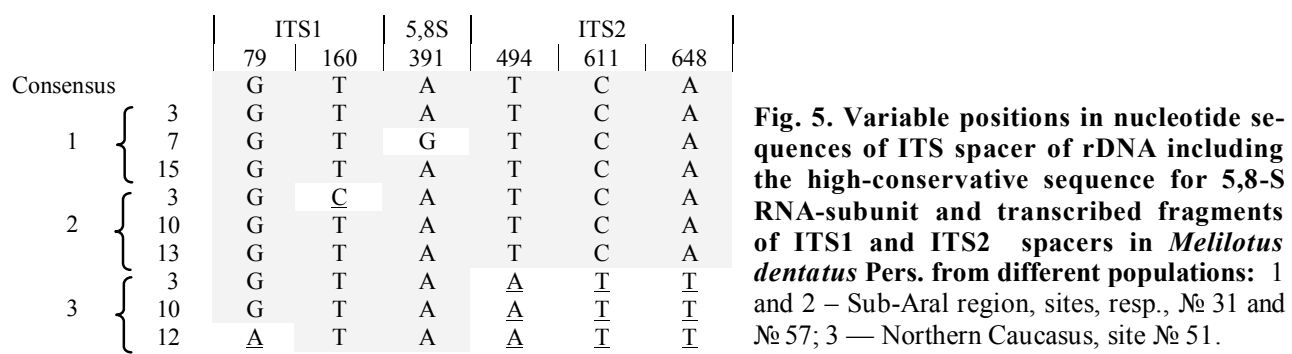

(the sites are shown with corresponding numbers of tested samples).

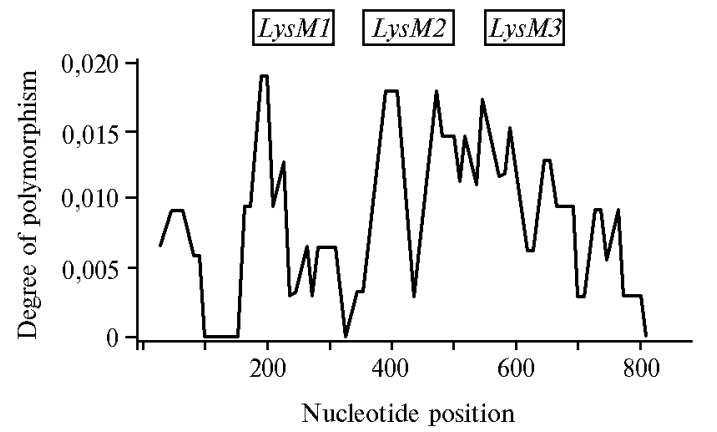

Fig. 6. Nucleotide polymorphism of domain structure in the receptor fragment of $n$ fr 5 gene of Melilotus dentatus Pers. plants of various geographical origin. LysM1, LysM2 and LysM3 - motifs of $n f r 5$ gene whose products provide interaction with bacterial signal.

During the molecular genetic analysis of $n f r 5$ gene, the obtained sequences of nucleotides and amino acids were aligned relative to the receptor fragment of $n f r 5$ gene of Galega orientalis Lam. In the studied populations of sweet clover, the domain structure of the studied gene fragment was determined, which was equal to $778 \mathrm{bp}$. The maximum number of variable sites was found in LysM-domains: in LysM1 and LysM2 - four, in LysM3 - three variable positions (Fig. 6, 7).

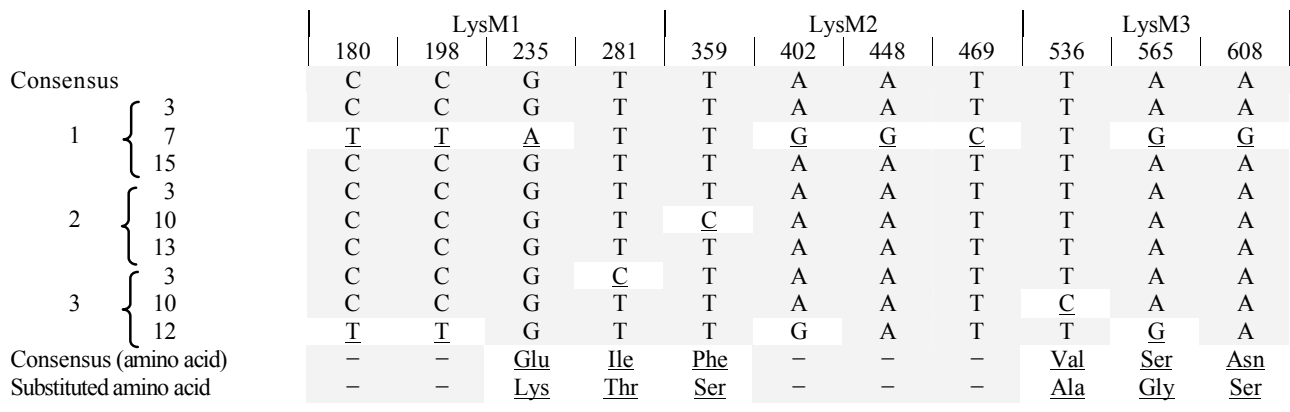

Fig. 7. Variable positions of nucleotide sequences and significant amino acid substitutions in the receptor fragment of $\boldsymbol{n f r} \mathbf{5}$ gene of Melilotus dentatus Pers. samples from different populations: 1 and 2 - Sub-Aral region, sites, resp., № 31 and № 57; 3 - Northern Caucasus, site № 51 (the sites are shown with numbers of tested samples).

The analysis of amino acid sequences showed that the number of sites with substitutions in domain LysM1 reduced to 2 , in LysM2 - to 1, while in LysM3 it remained unchanged equal to 3 (Fig. 7). The increased rate of non-synonymous (significant) substitutions in LysM3-domain may be the evidence of evolution of this gene through dynamic selection leading to many modifications of the plant receptor in interaction with bacterial signal.

Comparing the dendrograms constructed upon the data of nucleotide sequences in the receptor fragment of $n f r 5$ gene and ITS spacer (Fig. 4), it can be seen that the dendrogram of $n f r 5$ gene wasn't exactly close to RAPD- and ITS-dendrograms both consistent to each other, and it wasn't anyhow associated with geographical location of the studied populations. Probably, such variation of substitutions in the receptor fragment of $n f r 5$ gene occurred regardless of geographical origin of plants; this may reflect ecological plasticity of sweet clover in a changed environment, its ability to subtly respond and adapt to bacterial signals (Nod-factor), as well as the transfer of genetic material between populations.

The resulting nucleotide sequences of regions for ITS and $n f r 5$ gene of sweet clover were deposited in NCBI database with the following numbers:

$\begin{array}{lll}\text { (ITS_69/7-JF461307, } & \text { ITS_69/2-JF461308, } & \text { ITS_69/13-JF461309, } \\ \text { ITS_57/3-JF461310, } & \text { ITS_57/14-JF461311, } & \text { ITS_57/10-JF461312, } \\ \text { ITS_51/3-JF461313, } & \text { ITS_51/16-JF461314, } & \text { ITS_51/15-JF461315, } \\ \text { ITS_31/7-JF461316, } & \text { ITS_31/3-JF461317, } & \text { ITS_31/15-JF461318); } \\ \text { (NFR5_69/7-JF461295, } & \text { NFR5_69/2-JF461296, } & \text { NFR5_69/13-JF461297, } \\ \text { NFR5_57/3-JF461298, } & \text { NFR5_57/14-JF461299, } & \text { NFR5_57/10-JF461300, } \\ \text { NFR5_51/3-JF461301, } & \text { NFR5_51/16-JF461302, } & \text { NFR5_51/15-JF461303, } \\ \text { NFR5_31/7-JF461304, } & \text { NFR5_31/3-JF461305, } & \text { NFR5_31/15-JF461306). }\end{array}$

Thus, the studied populations of sweet clover Melilotus dentatus Pers. growing in geographically remote regions (Sub-Aral and the Northern Caucasus) were found to have a number of intra- and interpopulation differences, and they belong to different clusters according to their geographical distribution. It was revealed an independent distribution of populations for the receptor fragment of $n f r 5$ gene relative to the cluster structure for ITS spacer. The molecular genetic analysis of polymorphisms in symbiotic genes provides better understanding of biodiversity of economically important plants - promising genetic resources for bioengineering programs, and the data on co-evolutionary relations between macro- and microsymbionts are important for symbiogenetics as well. 


\section{REFERENCES}

1. Kirpichev I.V. and Naumov S.Yu., Odnoletniy i dvuletniy donnik (Annual and Biennial Melilot), Lugansk, 2002.

2. Suvorov V.V., Donnik (Melilot), Leningrad, 1962.

3. Madsen E.B., Madsen L.H., Radotoiu S., et al., A Receptor Kinase Gene of the LysM Type Is Involved in Legume Perception of Rhizobial Signals, Nature, 2003, vol. 425, pp. 637-640.

4. Markmann K., Giczey G., and Parniske M., Functional Adaptation of a Plant Receptor-Kinase Paved the Way for the Evolution of Intracellular Root Symbioses with Bacteria, PLoS Biol., 2008, vol. 6, pp. 496-506.

5. Radutoiu S., Madsen L.H., Madsen E.B., et al., Plant Recognition of Symbiotic Bacteria Requires Two LysM Receptor-Like Kinases, Nature, 2003, vol. 425, pp. $585-592$.

6. Limpens E., Franken C., Smit P., et al., LysM Domain Receptor Kinases Regulating Rhizobial Nod Factor-Induced Infection, Science, 2003, vol. 302, no. 5645, pp. 630-633.

7. Zhang X.-C., Cannon S.B., and Stacey G., Evolutionary Genomics of LysM Genes in Land Plants, BMC Evol. Biol., 2009 , vol. 9 , p. 183.

8. Carelli M., Gnocchi S., Fancelli S., et al., Genetic Diversity and Dynamics of Sinorhizobium Meliloti Populations Nodulating Different Alfalfa Cultivars in Italian Soils, Appl. Environ. Microbiol., 2000, vol. 66, no. 11, pp. 4785-4789.

9. Rogers S.O. and Bendich A.J., Extraction of DNA from Milligram Amounts of Fresh, Herbarium and Mummified Plant Tissues, Plant Mol. Biol., 1985, vol. 5, pp. 69-76.

10. Jones C.J., Edwards K.J., Castaglione S., et al., Reproducibility Testing of RAPD, AFLP and SSR Markers in Plants by a Network of European Laboratories, Mol. Breed., 1997, vol. 3, pp. 381-390.

11. Bena G., Lejeune B., Prosperi J.-M., and Olivieri I., Molecular Phylogenetic Approach for Studyinglife-History Evolution: the Aambiguous Example of the Genus Medicago L., Proc. R. Soc., 1998, vol. 265, pp. 1141-1151.

12. Baldwin B.G., Sanderson M.J., Porter J.M., et al., The ITS Region of Nuclear Ribosomal DNA: a Valuable Source of Evidence on Angiospermphylogeny, Ann. Missouri Bot. Gard., 1995, vol. 82, pp. 247-277. 